\title{
Common fixed point iterations for a class of multi-valued mappings in CAT $(0)$ spaces
}

Received: 21 July 2019 / Accepted: 20 July 2020 / Published online: 5 September 2020

(C) The Author(s) 2020

\begin{abstract}
In this work, we propose an iterative scheme to approach common fixed point(s) of a finite family of generalized multi-valued nonexpansive mappings in a $C A T(0)$ space. We establish and prove convergence theorems for the algorithm. The results are new and interesting in the theory of $C A T(0)$ spaces and are the analogues of corresponding ones in uniformly convex Banach spaces and Hilbert spaces.
\end{abstract}

Mathematics Subject Classification $47 \mathrm{H} 09 \cdot 47 \mathrm{H} 10$

\section{Introduction}

The theory of fixed point for multi-valued mappings has become of great interest to many researchers, see, for instance, $[3,4,8,11,13,15]$ and references therein. This concept contributes significantly in convex approximation, fractals, optimal control, digital imaging, and economics.

The following statements are quoted from [26]: "Sastry and Babu [21] showed that under certain conditions, Mann and Ishikawa iterative algorithms for a multi-valued nonexpansive mapping with a fixed point $x$ converge to a fixed point $y$ of the mapping. Panyanak [18] extended their results to a uniformly convex Banach space. Song and Wang [23] improved the results of Panyanak [18]. Abbas et al. [1] proposed a one-step iterative scheme to find a common fixed point of two multi-valued nonexpansive mappings in a uniformly convex Banach space. Recently, Uddin et al. [26] discovered a few gaps in the scheme proposed in [1] and came up with a new one-step iterative scheme for fixed points of two multi-valued nonexpansive mappings in $C A T(0)$ space and removed the gaps found in [1]".

Motivated by $[1,26]$, we recommend a new scheme to approximate common fixed point(s) of a finite family of generalized multi-valued nonexpansive mappings in $C A T(0)$ spaces.

\section{Preliminary lemmas}

We refer to [2] for the following definitions. "Suppose $(M, d)$ is a metric space and $a, b \in M$." A geodesic path from $a$ to $b$ is a mapping $s:[0, d(a, b)] \rightarrow X$, such that $s(0)=a, s(d(a, b))=b$ and $d\left(s(r), s\left(r^{\prime}\right)\right)=\left|r-r^{\prime}\right|$ for all $r, r^{\prime} \in[0, d(a, b)]$. A geodesic segment is defined as the image of the geodesic path. If every pair of points in $M$ is joined by a unique geodesic segment, then the space is known as unique geodesic metric

K. Saleh $(\varangle)$

Department of Mathematics and Statistics, King Fahd University of Petroleum and Minerals, Dhahran 31261, Saudi Arabia

E-mail: khairul@kfupm.edu.sa

H. Fukhar-ud-din

Department of Mathematics, The Islamia University of Bahawalpur, Bahawalpur 63100, Pakistan 
space. A geodesic triangle is denoted by $\Delta(a, b, c)$ in a geodesic metric space $(M, d)$ that consists of three points $a, b, c \in M$ (the vertices of the geodesic triangle $\Delta$ ) and three geodesic segments among these points. A comparison triangle for this geodesic triangle $\Delta(a, b, c)$ in $M$ is a triangle $\bar{\Delta}(\bar{a}, \bar{b}, \bar{c})$ in $\mathbb{R}^{2}$, such that $d_{\mathbb{R}^{2}}(\bar{i}, \bar{j})=d(i, j)$ for $i, j \in\{a, b, c\} . "$

Definition 2.1 [2] A geodesic space $M$ is a $C A T(0)$ space if, for each pair $(\Delta, \bar{\Delta}) \in X \times \mathbb{R}^{2}$, the following inequality:

$$
d_{\mathbb{R}^{2}}(\bar{a}, \bar{b}) \geq d(a, b)
$$

holds for all $\bar{a}, \bar{b} \in \bar{\Delta}$ and $a, b \in \Delta$.

Definition 2.2 [2] The geodesic segment from $a$ to $b$ is denoted by $[a, b]$, that is:

$$
[a, b]=\{\gamma a \oplus(1-\gamma) b: \gamma \in[0,1]\} .
$$

For $\gamma \in[0,1]$, we write $\gamma a \oplus(1-\gamma) b$ for the unique point $c$ on $[a, b]$, such that:

$$
d(a, c)=(1-\gamma) d(a, b) \text { and } d(b, c)=\gamma d(a, b) .
$$

Let $M$ be a $C A T(0)$ space. A subset $C$ of $M$ is convex if $[a, b] \subset C$ for all $a, b \in C$.

Definition 2.3 [13] For a fixed $x \in M$ and a bounded sequence $\left\{x_{n}\right\} \subset M$, we define:

$$
r\left(x,\left\{x_{n}\right\}\right)=\limsup _{n \rightarrow \infty} d\left(x_{n}, x\right) .
$$

The asymptotic radius of $\left\{x_{n}\right\}$ is defined by:

$$
r\left(\left\{x_{n}\right\}\right)=\inf _{x \in M} r\left(x,\left\{x_{n}\right\}\right)
$$

the asymptotic radius of $\left\{x_{n}\right\}$ with respect to $C \subset M$ is denoted by $r_{C}\left(\left\{x_{n}\right\}\right)$ and is defined by:

$$
r_{C}\left(\left\{x_{n}\right\}\right)=\inf _{x \in C} r\left(x,\left\{x_{n}\right\}\right) .
$$

The asymptotic center of $\left\{x_{n}\right\}$ is denoted by $A\left(\left\{x_{n}\right\}\right)$ and is given by the set:

$$
A\left(\left\{x_{n}\right\}\right)=\left\{\bar{x} \in X: r\left(\bar{x},\left\{x_{n}\right\}\right)=r\left(\left\{x_{n}\right\}\right)\right\} .
$$

The asymptotic center of $\left\{x_{n}\right\}$ with respect to $C \subset M$ is the set:

$$
A_{C}\left(\left\{x_{n}\right\}\right)=\left\{\bar{x} \in C: r\left(\bar{x},\left\{x_{n}\right\}\right)=r\left(\left\{x_{n}\right\}\right)\right\} .
$$

Definition 2.4 [14] A sequence $\left\{x_{n}\right\}$ in $M$ is said to be $\Delta$-convergent to the point $x \in M$ if $x$ is the unique asymptotic center of $\left\{u_{n}\right\}$ for every subsequence $\left\{u_{n}\right\}$ of $\left\{x_{n}\right\}$. We call $x$ the $\Delta$-limit of $\left\{x_{n}\right\}$ and express this limit as $\Delta-\lim _{n} x_{n}=x$.

It has been observed in [12] that "if $\left\{x_{n}\right\} \subset M$ and $\left\{x_{n}\right\}$ is $\Delta$-convergent to $x \in M$ and $\bar{x}(\neq x) \in M$, then:

$$
\limsup _{n \rightarrow \infty} d\left(x_{n}, x\right)<\limsup _{n \rightarrow \infty} d\left(x_{n}, \bar{x}\right) . "
$$

As mentioned in [12], "this concludes that $C A T(0)$ space satisfies a condition known as the Opial's property in Banach spaces".

Let $C$ be a nonempty subset of a metric space $(M, d)$. The set $C$ is called proximinal if for each $x \in M$, there exists $\bar{x} \in C$, such that $d(x, \bar{x})=\operatorname{dist}(x, C)$, where $\operatorname{dist}(x, C)=\inf _{z \in C} d(x, z)$. We denote the family of all bounded proximinal subsets of $C$ by $\mathcal{P}(C)$.

Let $\mathcal{C B}(C)$ and $\mathcal{K}(C)$ be families of nonempty, closed, and bounded subsets of $C$ and nonempty compact subsets of $C$, respectively. The Hausdorff metric $H$ on $\mathcal{C B}(C)$ is defined as:

$$
H(D, \bar{D})=\max \left\{\sup _{x \in \bar{D}} \operatorname{dist}(x, D), \sup _{\bar{x} \in D} \operatorname{dist}(\bar{x}, \bar{D})\right\} \text {, where } D, \bar{D} \in \mathcal{C B}(C) .
$$

An element $p \in C$ is a fixed point of $S: C \rightarrow \mathcal{C B}(C)$ if $p \in S p$. The set of all fixed points of $S$ is denoted by $F(S)$. 
Definition 2.5 [13] A mapping $S: C \rightarrow \mathcal{C B}(C)$ is a multi-valued nonexpansive if $H(S x, S y) \leq d(x, y)$ for all $x, y \in C$.

Definition 2.6 [22] A mapping $S: C \rightarrow \mathcal{C B}(C)$ is a multi-valued quasi-nonexpansive if $H(S x, S p) \leq d(x, p)$ for all $x \in C, p \in F(S)$.

Definition 2.7 [21] The mapping $S: C \rightarrow \mathcal{C B}(C)$ is called generalized multi-valued nonexpansive if

$$
\begin{aligned}
H(S x, S y) \leq & a_{1} d(x, y)+a_{2}[\operatorname{dist}(x, S x)+\operatorname{dist}(y, S y)] \\
& +a_{3}[\operatorname{dist}(x, S y)+\operatorname{dist}(y, S x)]
\end{aligned}
$$

for all $x, y \in C$ where $a_{1}+2 a_{2}+2 a_{3} \leq 1$.

Example 2.8 Let $G:[0,3] \rightarrow C B([0,3])$ be defined as under:

$$
G(x)= \begin{cases}{\left[0, \frac{x}{3}\right]} & \text { if } x \neq 3 \\ \{1.2\} & \text { if } x=3 .\end{cases}
$$

Then, $G$ is a generalized nonexpansive mapping with $F(G)=\{0\}$.

Verification: We first show that $G$ is nonexpansive $\left(a_{1}=1, a_{2}=0=a_{3}\right)$.

Case 1. If $x=y \neq 3$, then $H(G x, G y)=\left\|\frac{x}{3}-\frac{y}{3}\right\| \leq\|x-y\|$.

Case 2. If $x=3=y$, then $H(G x, G y)=0=\|x-y\|$.

Case 3. If $x \neq 3$ and $y=3$, then $H(G x, G y)=1.2-\frac{x}{3} \leq 3-x=\|x-y\|$. This relation holds if and only if $x \leq 2.7$. Hence, $G$ is a nonexpansive mapping.

For generalized nonexpansivity of $G$, we further investigate two cases.

Case 4. If $x \in[0,1.8)$ and $y \in[0,3)$, then this case is similar to Case 1 as mentioned above.

Case 5. If $x \in[1.8,3)$ and $y=3$ with $a_{1}=\frac{1}{8}=a_{2}$ and $a_{3}=\frac{1}{4}$, then we compute:

$$
H(G x, G y)=\left\|\frac{2 x}{3}-1.2\right\|= \begin{cases}0 & \text { if } x=1.8 \\ <0.8 & \text { if } x<3 .\end{cases}
$$

The other estimates are as follows:

1. $\|x-y\|=\|x-3\|$;

2. dist $(x, G x)=\left\|\frac{2 x}{3}\right\|$;

3. $\operatorname{dist}(y, G y)=\|3-1.2\|$;

4. dist $(x, G y)=\|x-1.2\|$;

5. dist $(y, G x)=\|3-[0,1)\|$.

Now, observe that:

$$
\begin{aligned}
a_{1} & \|x-y\|+a_{2}(\operatorname{dist}(x, G x)+\operatorname{dist}(y, G y))+a_{3}(\operatorname{dist}(x, G y)+\operatorname{dist}(y, G x)) \\
& =\frac{1}{8}\|x-3\|+\frac{1}{8}\left(\left\|\frac{2 x}{3}\right\|+1.8\right)+\frac{1}{4}(\|x-1.2\|+\|3-[0,1)\|) \\
& \geq \frac{1}{8}\|1.8-3\|+\frac{1}{8}\left(\left\|\frac{2(1.8)}{3}\right\|+1.8\right)+\frac{1}{4}(\|1.8-1.2\|+2) \\
& =\frac{1.2}{8}+\frac{3}{8}+\frac{2.6}{4} \\
& =1.175 .
\end{aligned}
$$

It follows from (2.2) and (2.3) that:

$$
\begin{aligned}
H(G x, G y) \leq & a_{1}\|x-y\|+a_{2}(\operatorname{dist}(x, G x)+\operatorname{dist}(y, G y)) \\
& +a_{3}(\operatorname{dist}(x, G y)+\operatorname{dist}(y, G x)) .
\end{aligned}
$$

Hence, $G$ is a generalized nonexpansive mapping. 
If we choose $a_{1}=1$ and $a_{2}=0=a_{3}$ in (2.1), it becomes multi-valued nonexpansive, but the converse does not hold, in general. Furthermore, we can verify that every generalized multi-valued nonexpansive mapping having at least one fixed point is multi-valued quasi-nonexpansive. For $x \in C, p \in F(S)$, we obtain:

$$
\begin{aligned}
H(S x, S p) \leq & a_{1} d(x, p)+a_{2}[\operatorname{dist}(x, S x)+\operatorname{dist}(p, S p)] \\
& +a_{3}[\operatorname{dist}(x, S p)+\operatorname{dist}(p, S x)] \\
\leq & a_{1} d(x, p)+a_{2}[d(x, p)+\operatorname{dist}(p, S x)]+a_{3}[d(x, p)+\operatorname{dist}(p, S x)] \\
\leq & \left(a_{1}+a_{2}+a_{3}\right) d(x, p)+\left(a_{2}+a_{3}\right) H(S x, S p) .
\end{aligned}
$$

That is:

$$
H(S x, S p) \leq \frac{a_{1}+a_{2}+a_{3}}{1-\left(a_{2}+a_{3}\right)} d(x, p) \leq d(x, p) .
$$

The following fixed point existence theorem has been proved by Lim [13].

Theorem 2.9 [13] Let $X$ be a uniformly convex Banach space and $C$ be a nonempty bounded, closed, and convex subset of $X$. Let $T: C \rightarrow \mathcal{K}(C)$ be a multi-valued nonexpansive mapping. Then, $T$ has a fixed point.

Due to the importance of fixed point problems, iterative schemes for approximating fixed points of multivalued mappings remain to be a flourishing subject in fixed point theory. Unfortunately, the existence result of common fixed points of a family of mappings is not known in many situations. Therefore, it is natural to consider approximation results for these classes of mappings, see, for example, [10,19,20,24,25]. Many iterative schemes have been introduced for different classes of mappings with a nonempty set of common fixed points. To define new iterative scheme, the following lemma will be needed.

Lemma 2.10 [16] Let $D, \bar{D} \in \mathcal{C B}(C)$ and $x \in D$. For every $\varepsilon>0$, there exists $y \in \bar{D}$, such that $d(x, y) \leq$ $H(D, \bar{D})+\varepsilon$.

Let $(M, d)$ be a $C A T(0)$ space. For $x_{i} \in M$ and $\alpha_{i} \in(0,1), i \in\{1,2, \ldots n\}$ and $\sum_{i=1}^{n} \alpha_{i}=1$, we can define, by induction, that:

$$
\bigoplus_{i=1}^{n} \alpha_{i} x_{i}=\left(1-\alpha_{n}\right)\left(\frac{\alpha_{1}}{1-\alpha_{n}} x_{1} \oplus \frac{\alpha_{2}}{1-\alpha_{n}} x_{2} \oplus \cdots \oplus \frac{\alpha_{n-1}}{1-\alpha_{n}} x_{n-1}\right) \oplus \alpha_{n} x_{n} .
$$

Now, we write up our new iterative scheme to approximate common fixed point of a finite family of multi-valued generalized nonexpansive mappings in a $C A T(0)$ space as follows:

Let $S_{1}, S_{2}, \ldots S_{m}: C \rightarrow \mathcal{C B}(C)$ be multi-valued generalized nonexpansive mappings, such that $\mathcal{F}=$ $\bigcap_{i \in J} F\left(S_{i}\right) \neq \phi$, where $J=\{1,2,3, \ldots, m\}$ (we assume it throughout the paper).

In view of Lemma 2.10, we define the scheme $\left\{x_{n}\right\}$ in $C$ as follows:

$$
x_{1} \in C, x_{n+1}=\bigoplus_{i=0}^{m} \alpha_{n, i} y_{n, i},
$$

where $y_{n, 0}=x_{n}, y_{n, i} \in S_{i} x_{n}$, such that:

$$
d\left(y_{n, i}, p\right) \leq H\left(S_{i} x_{n}, S_{i} p\right)+\varepsilon_{n, i} \text { for } i \in J \text { and } p \in \mathcal{F}
$$

with $\lim _{n \rightarrow \infty} \varepsilon_{n, i}=0$ and the sequences $\left\{\alpha_{n, 0}\right\},\left\{\alpha_{n, 1}\right\}, \ldots,\left\{\alpha_{n, m}\right\}$ are in $(0,1)$ with $\sum_{i=0}^{m} \alpha_{n, i}=1$.

We recall some needed propositions and lemmas.

Proposition 2.11 [7] If $\left\{x_{n}\right\}$ is a bounded sequence in a complete $C A T(0)$ space $M$ and if $C$ is nonempty closed convex subset of $M$, then there exists a unique point $u \in C$, such that:

$$
r\left(u,\left\{x_{n}\right\}\right)=\inf _{x \in C} r\left(x,\left\{x_{n}\right\}\right) .
$$

The above fact immediately yields the following proposition.

Proposition 2.12 [17] Let $\left\{x_{n}\right\}, C$ and $M$ be as in Proposition 2.11. Then, $A\left(\left\{x_{n}\right\}\right)$ and $A_{C}\left(\left\{x_{n}\right\}\right)$ are singleton. 
Lemma 2.13 [6,26] Let $M$ be a $C A T(0)$ space and $\left\{x, x_{1}, x_{2}, \ldots, x_{n}\right\} \subset M$. If $a_{i} \in(0,1)$ for $i=$ $1,2,3, \ldots, n$ with $\sum_{i=1}^{n} a_{i}=1$, then for each $i, j \in\{1,2, \ldots, n\}$, such that $i<j$, we have:

(a) $d\left(\bigoplus_{i=1}^{n} a_{i} x_{i}, x\right) \leq \sum_{i=1}^{n} a_{i} d\left(x_{i}, x\right)$

(b) $d\left(\bigoplus_{i=1}^{n} a_{i} x_{i}, x\right)^{2} \leq \sum_{i=1}^{n} a_{i} d\left(x_{i}, x\right)^{2}-a_{i} a_{j} d\left(x_{i}, x_{j}\right)^{2}$.

Lemma 2.14 [12] Every bounded sequence in a complete $C A T(0)$ space $M$ admits a $\Delta$-convergent subsequence.

Lemma 2.15 [5] Let $C$ be a closed and convex subset of a complete $C A T(0)$ space M. If $\left\{x_{n}\right\}$ is a bounded sequence in $C$, then the asymptotic center of $\left\{x_{n}\right\}$ lies in $C$.

In this paper, we prove some convergence theorems for a finite family of multi-valued generalized nonexpansive mappings using scheme (2.4). Our results generalize the corresponding results in $[1,26]$ and references cited therein.

\section{Convergence theorems}

We start with the following lemma.

Lemma 3.1 Let $C$ be a nonempty closed and convex subset of a complete C AT (0) space M. Let $S_{1}, S_{2}, \ldots S_{m}$ : $C \rightarrow \mathcal{C B}(C)$ be multi-valued generalized nonexpansive mappings, such that $S_{i} p=\{p\}$ for all $p \in \mathcal{F}$. If $\left\{x_{n}\right\}$ is a sequence in $C$ given by (2.4), then $\lim _{n \rightarrow \infty} d\left(x_{n}, p\right)$ exists for each $p \in \mathcal{F}$.

Proof Let $p \in \mathcal{F}$. Applying Lemma 2.13 (a) to the scheme (2.4), we have:

$$
\begin{aligned}
d\left(x_{n+1}, p\right) & =d\left(\bigoplus_{i=0}^{m} \alpha_{n, i} y_{n, i}, p\right) \\
& \leq \sum_{i=0}^{m} \alpha_{n, i} d\left(y_{n, i}, p\right) \\
& =\alpha_{n, 0} d\left(x_{n}, p\right)+\sum_{i=1}^{m} \alpha_{n, i} \operatorname{dist}\left(y_{n, i}, S_{i} p\right) \\
& \leq \alpha_{n, 0} d\left(x_{n}, p\right)+\sum_{i=1}^{m} \alpha_{n, i} H\left(S_{i} x_{n}, S_{i} p\right) \\
& \leq d\left(x_{n}, p\right) \sum_{i=0}^{m} \alpha_{n, i} \\
& =d\left(x_{n}, p\right) .
\end{aligned}
$$

That is, $\left\{d\left(x_{n}, p\right)\right\}$ is decreasing and bounded below. Hence, $\lim _{n \rightarrow \infty} d\left(x_{n}, p\right)$ exists.

Lemma 3.2 Let $C$ be a nonempty closed convex subset of a complete $C A T(0)$ space M. Let $S_{1}, S_{2}, \ldots S_{m}$ : $C \rightarrow \mathcal{C B}(C)$ be multi-valued generalized nonexpansive mappings, such that $S_{i} p=\{p\}$ for all $p \in \mathcal{F}$. If $\left\{x_{n}\right\}$ is a sequence in $C$ given by (2.4), where $\left\{\alpha_{n, 0}\right\},\left\{\alpha_{n, 1}\right\}, \ldots,\left\{\alpha_{n, m}\right\}$ are sequences in $[\delta, 1-\delta]$ for some $\delta \in\left(0, \frac{1}{2}\right)$, such that $\sum_{i=0}^{m} \alpha_{n, i}=1$, then $\lim _{n \rightarrow \infty} \operatorname{dist}\left(x_{n}, S_{j} x_{n}\right)=0$ for each $j \in J$.

Proof Let $p \in \mathcal{F}$. By the scheme (2.4) and Lemma 2.13 (b):

$$
\begin{aligned}
d\left(x_{n+1}, p\right)^{2} & =d\left(\bigoplus_{i=0}^{m} \alpha_{n, i} y_{n, i}, p\right)^{2} \\
& \leq \sum_{i=0}^{m} \alpha_{n, i} d\left(y_{n, i}, p\right)^{2}-\alpha_{n, 1} \alpha_{n, j} d\left(x_{n}, y_{n, j}\right)^{2}
\end{aligned}
$$




$$
\begin{aligned}
& \leq \alpha_{n, 0} d\left(x_{n}, p\right)^{2}+\sum_{i=1}^{m} \alpha_{n, i} H\left(S_{i} x_{n}, p\right)^{2}-\alpha_{n, 1} \alpha_{n, j} d\left(x_{n}, y_{n, j}\right)^{2} \\
& \leq \sum_{i=0}^{m} \alpha_{n, i} d\left(x_{n}, p\right)^{2}-\alpha_{n, 1} \alpha_{n, j} d\left(x_{n}, y_{n, j}\right)^{2} \\
& =d\left(x_{n}, p\right)^{2}-\alpha_{n, 1} \alpha_{n, j} d\left(x_{n}, y_{n, j}\right)^{2} .
\end{aligned}
$$

That is:

$$
\delta^{2} d\left(x_{n}, y_{n, j}\right)^{2} \leq d\left(x_{n}, p\right)^{2}-d\left(x_{n+1}, p\right)^{2} .
$$

For any positive integer $N \geq 1$, the above inequality provides that:

$$
\delta^{2} \sum_{n=1}^{N} d\left(x_{n}, y_{n, j}\right)^{2} \leq d\left(x_{1}, p\right)^{2}-d\left(x_{N+1}, p\right)^{2} \leq d\left(x_{1}, p\right)^{2}<\infty .
$$

If $N \rightarrow \infty$, we have $\delta^{2} \sum_{n=1}^{\infty} d\left(x_{n}, y_{n, j}\right)^{2}<\infty$.

Hence, for each $j \in\{1,2, \ldots m\}$, we deduce that:

$$
\lim _{n \rightarrow \infty} d\left(x_{n}, y_{n, j}\right)=0 .
$$

Since $\operatorname{dist}\left(x_{n}, T_{j} x_{n}\right) \leq d\left(x_{n}, y_{n, j}\right)$, it follows that:

$$
\lim _{n \rightarrow \infty} \operatorname{dist}\left(x_{n}, T_{j} x_{n}\right)=0 .
$$

Now, we prove the demiclosed principle for multi-valued generalized nonexpansive mappings.

Theorem 3.3 Let $C$ be a nonempty closed and convex subset of a complete CAT(0) space M. Let $S: C \rightarrow$ $\mathcal{K}(C)$ be a multi-valued generalized nonexpansive mapping and $\left\{x_{n}\right\} \subset C$. If $\Delta-\lim _{n} x_{n}=x \in C$ and $\lim _{n \rightarrow \infty} \operatorname{dist}\left(x_{n}, S x_{n}\right)=0$, then $x$ is a fixed point of $S$.

Proof For $n \geq 1$, choose $y_{n} \in S x$, such that $d\left(x_{n}, y_{n}\right)=\operatorname{dist}\left(x_{n}, S x\right)$ as $S x \in \mathcal{K}(C)$. By the compactness of $S x$, there exists a subsequence $\left\{y_{n_{i}}\right\}$ of $\left\{y_{n}\right\}$, such that $\lim _{i \rightarrow \infty} y_{n_{i}}=y \in S x$.

Now, we have:

$$
\begin{aligned}
d\left(x_{n_{i}}, y_{n_{i}}\right)= & \operatorname{dist}\left(x_{n_{i}}, S x\right) \\
\leq & \operatorname{dist}\left(x_{n_{i}}, S x_{n_{i}}\right)+H\left(S x_{n_{i}}, S x\right) \\
\leq & \operatorname{dist}\left(x_{n_{i}}, S x_{n_{i}}\right)+a_{1} d\left(x, x_{n_{i}}\right)+a_{2}\left[\operatorname{dist}\left(x_{n_{i}}, S x_{n_{i}}\right)+\operatorname{dist}(x, S x)\right] \\
& +a_{3}\left[\operatorname{dist}\left(x_{n_{i}}, S x\right)+\operatorname{dist}\left(x, S x_{n_{i}}\right)\right] \\
= & \left(1+a_{2}\right) \operatorname{dist}\left(x_{n_{i}}, S x_{n_{i}}\right)+a_{1} d\left(x, x_{n_{i}}\right) \\
& +a_{2}\left[d\left(x_{n_{i}}, x\right)+\operatorname{dist}\left(x_{n_{i}}, S x\right)\right] \\
& +a_{3}\left[\operatorname{dist}\left(x_{n_{i}}, S x\right)+d\left(x_{n_{i}}, x\right)+\operatorname{dist}\left(x_{n_{i}}, S x_{n_{i}}\right)\right] .
\end{aligned}
$$

Thus:

$$
\begin{aligned}
d\left(x_{n_{i}}, y_{n_{i}}\right) & =\operatorname{dist}\left(x_{n_{i}}, S x\right) \\
& \leq \frac{1+a_{2}+a_{3}}{1-\left(a_{2}+a_{3}\right)} \operatorname{dist}\left(x_{n_{i}}, S x_{n_{i}}\right)+\frac{a_{1}+a_{2}+a_{3}}{1-\left(a_{2}+a_{3}\right)} d\left(x_{n_{i}}, x\right) \\
& \leq \frac{1+a_{2}+a_{3}}{1-\left(a_{2}+a_{3}\right)} \operatorname{dist}\left(x_{n_{i}}, S x_{n_{i}}\right)+d\left(x_{n_{i}}, x\right) .
\end{aligned}
$$

Hence:

$$
\begin{aligned}
d\left(x_{n_{i}}, y\right) & \leq d\left(x_{n_{i}}, y_{n_{i}}\right)+d\left(y_{n_{i}}, y\right) \\
& \leq \frac{1+a_{2}+a_{3}}{1-\left(a_{2}+a_{3}\right)} \operatorname{dist}\left(x_{n_{i}}, S x_{n_{i}}\right)+d\left(x_{n_{i}}, x\right)+d\left(y_{n_{i}}, y\right) .
\end{aligned}
$$


Taking the superior limit on both sides of the above inequality, we obtain:

$$
\limsup _{i \rightarrow \infty} d\left(x_{n_{i}}, y\right) \leq \limsup _{i \rightarrow \infty} d\left(x_{n_{i}}, x\right)=r\left(x,\left\{x_{n_{i}}\right\}\right) .
$$

By the uniqueness of the asymptotic center, we have $x=y \in S x$.

Theorem 3.4 Let $C$ be a nonempty closed convex subset of a complete $C A T(0)$ space $M$. Let $S_{1}, S_{2}, \ldots S_{m}$ : $C \rightarrow \mathcal{K}(C)$ be multi-valued generalized nonexpansive mappings, such that $S_{i} p=\{p\}$ for all $p \in \mathcal{F}$. If $\left\{x_{n}\right\}$ is a sequence in $C$ given by (2.4), where $\left\{\alpha_{n, 0}\right\},\left\{\alpha_{n, 1}\right\}, \ldots,\left\{\alpha_{n, m}\right\}$ are sequences in $[\delta, 1-\delta]$ for some $\delta \in\left(0, \frac{1}{2}\right)$, such that $\sum_{i=0}^{m} \alpha_{n, i}=1$, then $\Delta-\lim _{n} x_{n}=x \in \mathcal{F}$.

Proof It follows from Lemma 3.1 that $\left\{x_{n}\right\}$ is bounded. By Proposition 2.11, $\left\{x_{n}\right\}$ has a unique asymptotic center; that is, $A_{C}\left(\left\{x_{n}\right\}\right)=\{x\}$ and $x \in C$. By Lemmas 2.14 and 2.15, there must be a subsequence $\left\{z_{n}\right\}$ of $\left\{x_{n}\right\}$, such that $\Delta-\lim _{n} z_{n}=z \in C$. Lemma 3.2 implies that $\lim _{n \rightarrow \infty} \operatorname{dist}\left(z_{n}, S_{j} z_{n}\right)=0$ for each $j \in J$. In view of Theorem 3.3, we have $S_{j} z=z$ for each $j \in J$. That is, $z \in \mathcal{F}$.

If $z \neq x$, by the uniqueness of the asymptotic center, we have:

$$
\begin{aligned}
\limsup _{n \rightarrow \infty} d\left(z_{n}, z\right)< & <\limsup _{n \rightarrow \infty} d\left(z_{n}, x\right) \leq \limsup _{n \rightarrow \infty} d\left(x_{n}, x\right) \\
< & \limsup _{n \rightarrow \infty} d\left(x_{n}, z\right)=\limsup _{n \rightarrow \infty} d\left(z_{n}, z\right),
\end{aligned}
$$

which is a contradiction and, hence, $z=x \in \mathcal{F}$.

Let $\left\{v_{n}\right\}$ be any subsequence of $\left\{x_{n}\right\}$, such that $A_{C}\left(\left\{v_{n}\right\}\right)=\{v\}$ and $v \in C$. Suppose $z \neq v$; we have:

$$
\begin{aligned}
\limsup _{n \rightarrow \infty} d\left(z_{n}, z\right) & <\limsup _{n \rightarrow \infty} d\left(z_{n}, v\right) \\
& \leq \limsup _{n \rightarrow \infty} d\left(v_{n}, v\right) \\
& <\limsup _{n \rightarrow \infty} d\left(v_{n}, z\right) \\
& =\limsup _{n \rightarrow \infty} d\left(x_{n}, z\right)=\limsup _{n \rightarrow \infty} d\left(z_{n}, z\right),
\end{aligned}
$$

which is a contradiction. Hence, $z=v=x \in \mathcal{F}$.

Theorem 3.5 Let $C$ be a nonempty closed convex subset of a complete $C A T(0)$ space M. Let $S_{1}, S_{2}, \ldots S_{m}$ : $C \rightarrow \mathcal{C B}(C)$ be multi-valued generalized nonexpansive mappings, such that $S_{i} p=\{p\}$ for all $p \in \mathcal{F}$. If $\left\{x_{n}\right\}$ is a sequence given by (2.4), where $\left\{\alpha_{n, 0}\right\},\left\{\alpha_{n, 1}\right\}, \ldots,\left\{\alpha_{n, m}\right\}$ are sequences in $[\delta, 1-\delta]$ for some $\delta \in\left(0, \frac{1}{2}\right)$, such that $\sum_{i=0}^{m} \alpha_{n, i}=1$, then $\left\{x_{n}\right\}$ converges to a point $p \in \mathcal{F}$ if and only if:

$$
\liminf _{n \rightarrow \infty} \operatorname{dist}\left(x_{n}, \mathcal{F}\right)=0 \text { or } \limsup _{n \rightarrow \infty} \operatorname{dist}\left(x_{n}, \mathcal{F}\right)=0 \text {. }
$$

Proof It is easy to see that if $\left\{x_{n}\right\}$ converges to a point $p \in \mathcal{F}$, then (3.1) holds.

Conversely, suppose that:

$$
\liminf _{n \rightarrow \infty} \operatorname{dist}\left(x_{n}, \mathcal{F}\right)=0 \text { or } \limsup _{n \rightarrow \infty} \operatorname{dist}\left(x_{n}, \mathcal{F}\right)=0 .
$$

Lemma 3.1 implies that:

$$
d\left(x_{n+1}, p\right) \leq d\left(x_{n}, p\right) \text { for any } p \in \mathcal{F},
$$

so that $\operatorname{dist}\left(x_{n+1}, \mathcal{F}\right) \leq \operatorname{dist}\left(x_{n}, \mathcal{F}\right)$.Thus, $\lim _{n \rightarrow \infty} \operatorname{dist}\left(x_{n}, \mathcal{F}\right)$ exists. Since:

$$
\liminf _{n \rightarrow \infty} \operatorname{dist}\left(x_{n}, \mathcal{F}\right)=0 \text { or } \limsup _{n \rightarrow \infty} \operatorname{dist}\left(x_{n}, \mathcal{F}\right)=0 \text {, }
$$

we have $\lim _{n \rightarrow \infty} \operatorname{dist}\left(x_{n}, \mathcal{F}\right)=0$. Let $\varepsilon>0$. We can find $n_{0} \geq 1$, such that:

$$
\operatorname{dist}\left(x_{n}, \mathcal{F}\right)<\frac{\varepsilon}{3}, \text { for all } n \geq n_{0} .
$$

Therefore, there exists $p \in \mathcal{F}$, such that:

$$
d\left(x_{n_{0}}, p\right)<\frac{\varepsilon}{2} \text {. }
$$


For $m \geq n_{0}, n \geq n_{0}$, we have that:

$$
d\left(x_{m+n}, x_{n}\right) \leq d\left(x_{m+n}, p\right)+d\left(x_{n}, p\right)<2 d\left(x_{n_{0}}, p\right)<\varepsilon .
$$

Thus, $\left\{x_{n}\right\}$ is a Cauchy sequence in the closed subset $C$ of $X$. This implies that $\left\{x_{n}\right\}$ converges to $x \in C$. For each $j \in\{1,2, \ldots m\}$ :

$$
\begin{aligned}
\operatorname{dist}\left(x, S_{j} x\right) \leq & d\left(x, x_{n}\right)+\operatorname{dist}\left(x_{n}, S_{j} x_{n}\right)+H\left(S_{j} x_{n}, S_{j} x\right) \\
\leq & d\left(x, x_{n}\right)+\operatorname{dist}\left(x_{n}, S_{j} x_{n}\right)+a_{2}\left[\operatorname{dist}\left(x_{n}, S_{j} x_{n}\right)+\operatorname{dist}\left(x, S_{j} x\right)\right] \\
& +a_{1} d\left(x_{n}, x\right)+a_{3}\left[\operatorname{dist}\left(x_{n}, S_{j} x\right)+\operatorname{dist}\left(x, S_{j} x_{n}\right)\right] \\
\leq & \frac{a_{1}+2 a_{3}+1}{1-\left(a_{2}+a_{3}\right)} d\left(x, x_{n}\right)+\frac{a_{2}+a_{3}+1}{1-\left(a_{2}+a_{3}\right)} \operatorname{dist}\left(x_{n}, S_{j} x_{n}\right) \rightarrow 0,
\end{aligned}
$$

as $n \rightarrow \infty$. Hence, $S_{j} x=x$ for each $j \in J$. That is, $x \in \mathcal{F}$.

Definition 3.6 A finite family of multi-valued mappings $S_{1}, S_{2}, \ldots S_{m}: C \rightarrow \mathcal{C B}(C)$ satisfies condition (AV) if there exists a nondecreasing function $f:[0, \infty) \rightarrow[0, \infty)$, such that $f(0)=0, f(t)>0$ for $t>0$, and

$$
\frac{1}{m} \sum_{i=1}^{m} \operatorname{dist}\left(x, S_{i} x\right) \geq f(\operatorname{dist}(x, \mathcal{F})), \quad x \in C .
$$

The following theorem states the strong convergence of the algorithm.

Theorem 3.7 Let $C$ be a nonempty closed and convex subset of a complete $C A T(0)$ space $M$. Let $S_{1}, S_{2}, \ldots S_{m}: C \rightarrow \mathcal{C B}(C)$ be multi-valued generalized nonexpansive mappings satisfying condition( $\left.A V\right)$ and $S_{i} p=\{p\}$ for all $p \in \mathcal{F}$. If $\left\{x_{n}\right\}$ is a sequence given by (2.4) and $\left\{\alpha_{n, 0}\right\},\left\{\alpha_{n, 1}\right\}, \ldots,\left\{\alpha_{n, m}\right\}$ are sequences in $[\delta, 1-\delta]$ for some $\delta \in\left(0, \frac{1}{2}\right)$ such that $\sum_{i=0}^{m} \alpha_{n, i}=1$, then $\left\{x_{n}\right\}$ converges to a point $p \in \mathcal{F}$.

Proof As a consequence of Lemma 3.1, $\lim _{n \rightarrow \infty} \operatorname{dist}\left(x_{n}, \mathcal{F}\right)$ exists.

By condition (B):

$$
\lim _{n \rightarrow \infty} f\left(\operatorname{dist}\left(x_{n}, \mathcal{F}\right)\right) \leq \frac{1}{m} \sum_{i=1}^{m} \lim _{n \rightarrow \infty} \operatorname{dist}\left(x_{n}, S_{i} x\right)=0 .
$$

That is, $\lim _{n \rightarrow \infty} f\left(\operatorname{dist}\left(x_{n}, \mathcal{F}\right)\right)=0$. Since $f$ is a nondecreasing and $f(0)=0, \lim _{n \rightarrow \infty} \operatorname{dist}\left(x_{n}, \mathcal{F}\right)=$ 0.The conclusion follows from Theorem 3.5.

\section{Common fixed points on proximinal subsets}

Let $S_{1}, S_{2}, \ldots S_{m}: C \rightarrow \mathcal{P}(C)$ be multi-valued generalized nonexpansive mappings. For $x_{1} \in C$ and $i \in J$. As $S_{i} x_{1}$ is a proximinal subset of $C$, there exists $y_{1, i} \in S_{i} x_{1}$, such that $d\left(q, y_{1, i}\right)=\operatorname{dist}\left(q, S_{i} x_{1}\right)$ whenever $q$ is a fixed point of $S_{i}$. Hence, our scheme 2.4 reads as follows:

$$
x_{n+1}=\bigoplus_{i=0}^{m} \alpha_{n, i} y_{n, i},
$$

where $y_{n, 0}=x_{n}$. For $i \in J, y_{n, i} \in S_{i} x_{n}$ with $d\left(q, y_{n, i}\right)=\operatorname{dist}\left(q, S_{i} x_{n}\right)$ for $p \in \mathcal{F}$. Moreover, $\left\{\alpha_{n, 0}\right\},\left\{\alpha_{n, 1}\right\}, \ldots,\left\{\alpha_{n, m}\right\}$ are sequences in $(0,1)$, such that $\sum_{i=0}^{m} \alpha_{n, i}=1$.

Using the scheme (4.1), we can prove the following results whose proofs carry on similar details to those in Sect. 2. In the following results, assume that $C$ is a nonempty, convex, and closed subset of the space $M$.

Lemma 4.1 Let $S_{1}, S_{2}, \ldots S_{m}: C \rightarrow \mathcal{P}(C)$ be multi-valued generalized nonexpansive mappings. If $\left\{x_{n}\right\}$ is a sequence given by (4.1), then $\lim _{n \rightarrow \infty} d\left(x_{n}, q\right)$ exists for each $q \in \mathcal{F}$.

Lemma 4.2 Let $S_{1}, S_{2}, \ldots S_{m}: C \rightarrow \mathcal{P}(C)$ be multi-valued generalized nonexpansive mappings. If $\left\{x_{n}\right\}$ is a sequence given by (4.1), where $\left\{\alpha_{n, 0}\right\},\left\{\alpha_{n, 1}\right\}, \ldots,\left\{\alpha_{n, m}\right\}$ are sequences in $[\delta, 1-\delta]$ for some $\delta \in\left(0, \frac{1}{2}\right)$, such that $\sum_{i=1}^{m+1} \alpha_{n, i}=1$, then $\lim _{n \rightarrow \infty} \operatorname{dist}\left(x_{n}, S_{j} x_{n}\right)=0$ for $j \in J$. 
Theorem 4.3 Let $S_{1}, S_{2}, \ldots S_{m}: C \rightarrow \mathcal{P}(C)$ be multi-valued generalized nonexpansive mappings. If $\left\{x_{n}\right\}$ is a sequence given by (4.1) where $\left\{\alpha_{n, 0}\right\},\left\{\alpha_{n, 1}\right\}, \ldots,\left\{\alpha_{n, m}\right\}$ are sequences in $[\delta, 1-\delta]$ for some $\delta \in\left(0, \frac{1}{2}\right)$ with $\sum_{i=1}^{m+1} \alpha_{n, i}=1$, then $\left\{x_{n}\right\}$ converges to a point $q \in \mathcal{F}$ if and only if:

$$
\liminf _{n \rightarrow \infty} \operatorname{dist}\left(x_{n}, \mathcal{F}\right)=0 \text { or } \limsup _{n \rightarrow \infty} \operatorname{dist}\left(x_{n}, \mathcal{F}\right)=0 .
$$

Theorem 4.4 Let $S_{1}, S_{2}, \ldots S_{m}: C \rightarrow \mathcal{P}(C)$ be multi-valued generalized nonexpansive mappings satisfying condition (B). If $\left\{x_{n}\right\}$ is a sequence given by (4.1) where $\left\{\alpha_{n, 0}\right\},\left\{\alpha_{n, 1}\right\}, \ldots,\left\{\alpha_{n, m}\right\}$ are sequences in $[\delta, 1-\delta]$ for some $\delta \in\left(0, \frac{1}{2}\right)$, such that $\sum_{i=1}^{m+1} \alpha_{n, i}=1$, then the sequence $\left\{x_{n}\right\}$ converges to a point $q \in \mathcal{F}$.

Remark 4.5 The above theorems are new in $C A T(0)$ spaces and reform the results of Abbas et al. [1], Khan and Fukhar-ud-din [9] and some others. The reason is that we consider a nonlinear space, a family of generalized multi-valued nonexpansive mappings and a one-step iterative scheme (instead of multi-step).

Acknowledgements The first author is grateful to King Fahd University of Petroleum and Minerals (KFUPM), Saudi Arabia for supporting this research.

Open Access This article is licensed under a Creative Commons Attribution 4.0 International License, which permits use, sharing, adaptation, distribution and reproduction in any medium or format, as long as you give appropriate credit to the original author(s) and the source, provide a link to the Creative Commons licence, and indicate if changes were made. The images or other third party material in this article are included in the article's Creative Commons licence, unless indicated otherwise in a credit line to the material. If material is not included in the article's Creative Commons licence and your intended use is not permitted by statutory regulation or exceeds the permitted use, you will need to obtain permission directly from the copyright holder. To view a copy of this licence, visit http://creativecommons.org/licenses/by/4.0/.

\section{References}

1. Abbas, M.; Khan, A.R.; Khan, A.R.P.: Common fixed points of two multivalued nonexpansive mappings by one-step iterative scheme. Appl. Math. Lett. 24, 97-102 (2011)

2. Bridson, M.; Haefliger, A.: Metric Spaces of Non-Positive Curvature. Springer, Berlin (1999)

3. Browder, F.E.: Nonlinear operators and nonlinear equations of evolution in Banach spaces. In: Nonlinear Functional Analysis (Proc. Sympos. PureMath., vol. 18, Part 2, Chicago, III., 1968). American Mathematical Society, Rhode Island, pp. 1-308 (1976)

4. Dozo, E.L.; EL, : Multi-valued nonexpansive mappings and Opial's condition. Bull. Am. Math. Soc. 38, $286-292$ (1973)

5. Dhompongsa, S.; Panyanak, B.: on $\Delta$-convergence theorems in CAT(0) space. Comput. Math. Appl. 56, 2572-2579 (2008)

6. Dhompongsa, S.; Kaewkhao, A.; Panyanak, B.: On Kirk's strong convergence theorem for multivalued nonexpansive mappings on CAT(0) spaces. Nonlinear Anal. 75, 459-568 (2012)

7. Dhompongsa, S.; Kirk, W.A.; Sims, B.: Fixed points of uniformly lipschitzian mappings. Nonlinear Anal. 65, 762-772 (2006)

8. Kaczynski, T.: Multivalued maps as a tool in modeling and rigorous numerics. J. Fixed Point Theory Appl. 4, 151-176 (2008)

9. Khan, S.H.; Fukhar-ud-din, H.: Weak and strong convergence of a scheme with errors for two nonexpansive mappings. Nonlinear Anal. 8, 1295-1301 (2005)

10. Kuhfittig, P.K.F.: Common fixed points of nonexpansive mappings by iterations. Pac. J. Math. 97(1), 137-139 (1981)

11. Kirk, W.A.; Massa, S.: Remarks on asymptotic and Chebyshev centers. Houston J. Math. 16, 357-364 (1990)

12. Kirk, W.A.; Panyanak, B.: A concept of convergence in geodesic spaces. Nonlinear Anal. 68, 3689-3696 (2008)

13. Lim, T.C.: A fixed point theorem for multivalued nonexpansive mappings in a uniformly convex Banach space. Bull. Am. Math. Soc. 80(6), 1123-1126 (1974)

14. Lim, T.C.: Remarks on some fixed point theorems. Proc. Am. Math. Soc. 60, 179-182 (1976)

15. Markin, J.T.: A fixed point theorem for set valued mappings. Bull. Am. Math. Soc. 74, 639-640 (1968)

16. Nadler Jr., S.B.: Multivalued contraction mappings. Pac. J. Math. 30, 475-488 (1969)

17. Nanjaras, B.; Panyanak, B.: Demiclosed principle for asymptotically nonexpansive mappings in CAT(0) spaces. Fixed Point Theory Appl. 2010, 14 (2010). (Article ID 268780)

18. Panyanak, B.: Mann and Ishikawa iterative processes for multivalued mappings in Banach spaces. Comput. Math. Appl. 54, 872-877 (2007)

19. Rhoades, B.E.: Finding common fixed points of nonexpansive mappings by iterations. Bull. Austral. Math. Soc. 62, 307-310 (2000)

20. Rhoades, B.E.: Finding common fixed points of nonexpansive mappings by iterations, Corrigendum. Bull. Austral. Math. Soc. 63, 345-346 (2001)

21. Sastry, K.P.R.; Babu, G.V.R.: Convergence of Ishikawa iterates for a multi-valued mapping with a fixed point. Chech. Math. J. 55, 817-826 (2005)

22. Shahzad, N.; Zegeye, H.: On Mann and Ishikawa iteration schemes for multivalued maps in Banach spaces. Nonlinear Anal. 71(3-4), 838-844 (2009)

23. Song, Y.; Wang, H.: Erratum to Mann and Ishikawa iterative processes for multi-valued mappings in Banach spaces. Comp. Math. Appl. 55, 2999-3002 (2008) 
24. Senter, H.F.; Dotson Jr., W.G.: Approximating fixed points of nonexpansive mappings. Proc. Am. Math. Soc. 44, 375-380 (1974)

25. Takahashi, W.; Shimoji, K.: Convergence theorems for nonexpansive mappings and feasibility problems. Math. Comput. Model. 32, 1463-1471 (2000)

26. Uddin, I.; Nieto, J.J.; Ali, J.: One-step iteration scheme for multivalued nonexpansive mappings in CAT( 0 ) spaces. Mediterr. J. Math. 13, 1211-1225 (2016)

Publisher's Note Springer Nature remains neutral with regard to jurisdictional claims in published maps and institutional affiliations. 